\title{
KEEFEKTIFAN MODEL PEMBELAJARAN REALISTIC MATHEMATIC EDUCATION DAN MODEL PEMBELAJARAN SNOWBALL THROWING BERBANTU MEDIA MAGIC CIRCLE TERHADAP HASIL BELAJAR
}

\author{
Dika Dwi Ariyanto \\ Fakultas Ilmu Pendidikan, Universitas PGRI Semarang \\ dikadwiariyanto17@gmail.com \\ Ali Shodiqin \\ Fakultas Ilmu Pendidikan, Universitas PGRI Semarang \\ alishodiqin@gmail.com
}

Aries Tika Damayani Fakultas Ilmu Pendidikan, Universitas PGRI Semarang ariestika@gmail.com

\begin{abstract}
Abstrak
Penelitian ini bertujuan untuk meningkatkan hasil belajar siswa materi bangun ruang dengan menggunakan model pembelajaran Ralistic Mathematic Education dan model pembelajaran Snowball Throwing berbantu media Magic Circle. Penelitian ini merupakan penelitian kuantitatif dengan desain penelitian pre-experimental design dengan bentuk nonequivalent control group pretest-posttest design. Subjek yang digunakan adalah siswa kelas VA, VB, dan VC. SD N Tamansari Mranggen Demak yang berjumlah total 56 dengan menggunakan teknik sampling acak. Teknik pengumpulan data menggunakan observasi, tes dan dokumentasi. Hasil penelitian menunjukkan nilai rata-rata pretest pada kelas kontrol 36,00 dan hasil nilai rata-rata pretest kelas eksperimen 1. 47,70 dan hasil nilai rata-rata pretest kelas eksperimen 2. 42,12. Sedangkan hasil nilai rata-rata pada posttest kelas kontrol 62,67 dan hasil nilai rata-rata posttest kelas eksperimen 1. 79,11 dan hasil nilai rata-rata posttest kelas eksperimen 2. 76,00. Hal tersebut dibuktikan dengan hasil uji t dimana jumlah kelas eksperimen 1. $t_{\text {hitung }}(2,718)>t_{\text {tabel }}(2,021)$. Dan juga jumlah kelas eksperimen 2 . $t_{\text {hitung }}(2,257)>t_{\text {tabel }}(2,021)$ Sehingga hasil belajar siswa kelas V SD N Tamansari Mranggen mengalami peningkatan.
\end{abstract}

Kata Kunci : Hasil Belajar Siswa, Model Realistic Mathematic dan Snowball Throwing, Magic Circle, Sekolah Dasar.

\begin{abstract}
Abstrak
This study aims to improve student learning outcomes of material in the building space using the Ralistic Mathematic Education learning model and the Snowball Throwing learning model assisted by the Magic Circle media. This research is a quantitative study with a pre-experimental design research design in the form of a non-equivalent control group pretestposttest design. The subjects used were VA, VB, and VC grade students. N Tamansari Mranggen Demak Elementary School totaling a total of 56 using random sampling techniques. Data collection techniques using observation, tests and documentation. The results showed the average value of the pretest in the control class 36.00 and the results of the average value of the experimental class pretest 1.47 .70 and the average value of the experimental class pretest 2. 42.12. While the results of the average value of the control class posttest 62.67 and the results of the average value of the experimental class posttest 1.79 .11 and the average value of the experimental class posttest 2.76 .00 . This is evidenced by the results of the $t$ test in which the number of experimental classes 1. $t_{-}$(count) $(2,718)>t_{-}$(table) $(2,021)$. And also the number of experimental classes 2. t_ (count) $(2,257)>t_{-}$(table) $(2,021)$ So that the learning outcomes of fifth grade students at SD N Tamansari Mranggen have increased.
\end{abstract}

Keywords: Student Learning Outcomes, Realistic Mathematic Models and Snowball Throwing, Magic Circle, Elementary Schools . 


\section{Pendahuluan.}

Proses pendidikan yang terjadi di Indonesia ialah masih kurangnya penghargaan yang sesuai dengan apa yang telah diberikan oleh tenaga pendidik yaitu guru, yang menjadikan tenaga pendidik kurang maksimal dalam pembelajaran. Di sisi lain guru adalah salah satu dari sekian banyak faktor penentu keberhasilan dalam pendidikan. Guru SD juga telah melakukan berbagai upaya dalam pembelajaran yang menarik, interaktif, dan juga menyenangkan agar siswa dapat menerima materi yang telah di berikan oleh guru dengan baik.

Di Sekolah Dasar (SD), guru haruslah menguasai dan mampu mengajarkan pembelajaran sesuai dengan kurikulum saat ini yaitu K13 Kurikulum 2013 yang didalamnya mengajarkan pembelajaran secara tematik. Pembelajaran tematik adalah pembelajaran terpadu yang menggunakan tema untuk mengkaitkan beberapa mata pelajaran sehingga menciptakan pengalaman yang berharga bagi para siswa. Pembelajaran tematik menuntut penggunaan pancaindra, melakukan tindakan nyata, dan observasi faktual dari siswa, mengangkat sisi penasaran dan intelektualitas dengan mendorong nalar, bereksperimen, dan mengkomunikasikan kepada orang lain. Dipembelajaran tematik juga berpusat kepada anak yang memberikan pengalaman langsung, tidak terjadi pemisahan materi dan menekankan lebih kepada proses dari pada hasil. Matematika yang mengajarkan siswa berpikir logis, analitis, sistematis, kritis dan kreatif.

Matematika merupakan mata pelajaran yang memuat aspek kognitif dan afektif didalamnya. Pada aspek kognitif matematika bertujuan mengembangkan potensi siswa dalam pemecahan masalah, dan pada aspek afektif siswa diajarkan mengembangkan ketelitian dan kesabaran didalam pemecahan masalah yang berhubungan dengan angka-angka. Siswa akan lebih cepat memahami matematika dengan cara selalu melakukan latihanlatihan dan juga percobaan secara mandiri dengan bimbingan seorang guru.

Dalam Model pembelajaran matematika salah satunya adalah realistic mathematic education (RME). Realistic Mathematic Education adalah suatu Model yang dilakukan guru dalam pembelajaran untuk memotivasi siswa agar memahami konsep matematika, dengan cara mengaitkan konsep ini dengan pengalaman atau kehidupan sehari-hari. Model pembelajaran Realistic Mathematic Education adalah Model pembelajaran dengan pengetahuan matematika yang konkret. Dengan mengaitkan dengan pengalaman dan kehidupan sehari-hari, hal ini akan menjadi kesan tersendiri bagi siswa. Siswa bisa langsung membayangkan secara nyata pengalaman atau kejadian yang telah dialaminya, agar mudah memahami materi yang diberikan oleh guru. Dengan Model ini guru juga akan mendapatkan hasil yang sesuai dengan materi yang telah diberikan kepada siswa tentang konsep matematika. Menjadikan pembelajaran matematika lebih menarik dan berkesan, jauh dari kata menakutkan ataupun membosankan. Pembelajaran juga akan menjadi lebih interaktif antara guru dan siswa, dan menambah motivasi siswa dalam mengikuti pembelajaran matematika.

Media Pembelajaran Salah satu unsur yang tidak dapat dipisahkan dari model pembelajaran adalah media pembelajaran, media pembalajaran adalah alat bantu proses belajar mengajar, yang digunakan oleh guru untuk mempermudah atau memperjelas tentang materi yang akan disampaikan lebih efektif dan efisisien. Contohnya media Magic Circle, media ini berbentuk Lingkaran di mana di dalamnya terdapat gambar untuk menjelaskan materi. Media ini tergolong dalam media berbasis visual, media berbasis visual memiliki peranan penting dalam proses pembelajaran. Media Magic Circle biasanya berukuran $45 \mathrm{~cm}$ namun hal ini disesuaikan dengan kebutuhan media itu sendiri.

Hasil belajar adalah kemampuan-kemampuan yang dimiliki siswa setelah ia menerima pengalaman belajarnya (Sudjana, 2013: 22). Menurut Dimyati dan Mudjiono (2009: 250) "hasil belajar merupakan hal yang dapat dipandang dari dua sisi yaitu siswa dan dari sisi guru”. Jika ingin mendapatkan hasil yang baik dalam pembelajaran harus ada koordinasi antara pihak pihak yang terkait guna menciptakan kerjasama. kerjasama dilakukan guru dengan siswa melalu pedekatan-pendekatan agar memperolah hasil yang baik. Agar siswa nyaman guru harus melakukan inovasi dalam pembelajaran untuk menciptakan pembelajaran yang menyenangkan, efektif, dan efisien.

Berdasarkan hasil observasi kepada guru kelas V di SD N Tamansari Mranggen Demak, menjelaskan bahwa guru memang belum semuanya menguasai dengan pendekatan, metode, dan model-model dalam pembelajaran. sebelumnya memang belum pernah menerapkan Model Pembelajaran Realistic Mathematic Education dan Model Pembelajaran Snowball Throwing berbantu media Magic Circle dalam pembelajaran matematika. pada pembelajaran yang telah di lakukan masih menggunakan model pembelajaran konvensional seperti, ceramah, tanya jawab, diskusi. Sehingga proses penyampaian materi dalam pembelajaran kurang bervariasi sehingga kurang maksimal dalam tujuan pembelajaran yang diharapkan.

Tabel 1. Hasil Observasi Awal

\begin{tabular}{cccc}
\hline Nilai Siswa $(\mathrm{x})$ & Jumlah Siswa & Prosentase & Keterangan \\
\hline$(\mathrm{x})<75$ & 17 & $63 \%$ & Tidak Tuntas \\
$(\mathrm{x}) \geq 75$ & 10 & $37 \%$ & Tuntas \\
\hline
\end{tabular}


Berdasarkan Tabel diatas dapat diketahui hasilnya pada hasil belajar Ulangan Tengah Semester (UTS) mata pelajaran matematika 27 jumlah siswa,17 siswa belum tuntas atau $63 \%$ dalam minimal kkm 75 . Rata-rata nilai kelas V adalah hasil observasi dengan Ibu Retno Cahyanti S.Pd. sebagian besar siswa masih belum mencapai minimal kkm dipelajaran matematika.

Latar belakang dia atas, peneliti akan melakukan penelitian yang berjudul " Keefektifan Model Pembelajaran Realistic Mathematic Education dan Model Pembelajaran Snowball Throwing berbantu media Magic Circle terhadap Hasil belajar Siswa Kelas V SD N Tamansari Mranggen Demak”.

\section{Metode}

Penelitian yang dilakukan merupakan penelitian kuantitatif. (Sugiyono,2016:6) Metode peneletian kuantitatif adalah metode penelitian yang berlandaskan pada filsafat positivisme, digunakan untuk meneliti pada populasi atau sampel tertent, teknik pengambilan sampel pada umumnya dilakukan secara random, pengumpulan data menggunakan instrumen penelitian analisis data bersifat kuantitatif/statistic dengan tujuan menguji, hipotesis yang telah ditetapkan. Metode yang digunakan dalam penelitian ini adalah metode Eksperimen Quasi. Desain yang digunakan dalam penelitian ini adalah non-equivalent control group pre-test post-test design (Sugiyono, 2017: 116). Dalam desain ini tiga kelompok dipilih secara random. Dengan desain ini sampel dibagi menjadi 3 kelompok yaitu kelas kontrol, kelas eksperimen 1, dan kelas eksperimen 2.

Teknik pengumpulan data dalam penelitian ini bertujuan untuk memperoleh memperoleh data yang relevan, akurat, dan reliabel. yang dilakukan peneliti diantaranya observasi, tes dan dokumentasi. Teknik tes digunakan untuk memperoleh data hasil belajar matematika materi bangun ruang siswa kelas V SD N Tamansari Mranggen Demak.

\section{Hasil Dan Pembahasan}

Berdasarkan hasil penelitian ini berupa data hasil pre-test dan post-test baik dalam kelas kontrol maupun eksperimen dapat diketahui bahwa terdapat nilai tertinggi dan nilai terendah, dan nilai rata-rata hasil penelitian pre-test dan post test. Deskripsi data pre-test dan post-test siswa. Data hasil penelitian disajikan dan di jelaskan dalam tabel sebagai berikut:

Tabel 2. Siswa Kelas V SD N Tamansari Hasil Analisis Uji Normalitas Data Awal

\begin{tabular}{llllrl}
\hline \multicolumn{1}{c}{ Kelas } & & $\mathrm{L}_{0}$ & $\mathrm{~L}_{\text {tabel }}$ & Keterangan & Kesimpulan \\
\hline Kontrol & 2 & 0,140 & 0,242 & $\mathrm{~L}_{0} \leq \mathrm{L}_{\text {tabel }}$ & Normal \\
Eksperimen 1 & 7 & 0,109 & 0,171 & $\mathrm{~L}_{0} \leq \mathrm{L}_{\text {tabel }}$ & Normal \\
Eksperimen 2 & 7 & 0,150 & 0,161 & $\mathrm{~L}_{0} \leq \mathrm{L}_{\text {tabel }}$ & Normal \\
\hline
\end{tabular}

Berdasarkan tabel 1 diatas diperoleh taraf signifikan 5\% didapat bahwa

$\mathrm{L}_{0} \leq \mathrm{L}_{\text {tabel. }}$. kelas kontrol $\mathrm{L}_{0}=0,140 \leq \mathrm{L}_{\text {tabel }}=0,242$,

kelas eksperimen $1 \mathrm{~L}_{0}=0,109 \leq \mathrm{L}_{\text {tabel }}=0,171$,

dan kelas eksperimen $2 \mathrm{~L}_{0}=0,150 \leq \mathrm{L}_{\text {tabel }}=0,161$.

Maka $\mathrm{H}_{0}$ diterima sehingga sampel berdistribusi normal.

Tabel 3. Siswa Kelas V SD N Tamansari Hasil Analisis Uji Normalitas Data Akhir

\begin{tabular}{llllrc}
\hline Kelas & & $\mathrm{L}_{0}$ & $\mathrm{~L}_{\text {tabel }}$ & Keterangan & Kesimpulan \\
\hline Kontrol & 2 & 0,212 & 0,242 & $\mathrm{~L}_{0} \leq \mathrm{L}_{\text {tabel }}$ & Normal \\
Eksperimen 1 & 7 & 0,100 & 0,171 & $\mathrm{~L}_{0} \leq \mathrm{L}_{\text {tabel }}$ & Normal \\
Eksperimen 2 & 7 & 0,131 & 0,161 & $\mathrm{~L}_{0} \leq \mathrm{L}_{\text {tabel }}$ & Normal \\
\hline
\end{tabular}

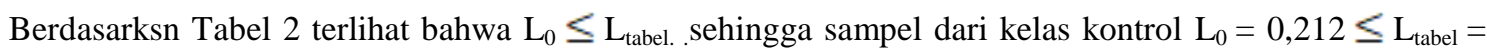
0,242 , kelas eksperimen $1 . \mathrm{L}_{0}=0,100 \leq \mathrm{L}_{\text {tabel }}=0,171$, dan kelas eksperimen $2 . \mathrm{L}_{0}=0,131 \leq \mathrm{L}_{\text {tabel }}=0,161$, Maka $\mathrm{H}_{0}$ diterima sehingga sampel berdistribusi normal. 
Tabel 4. Siswa Kelas V SD N Tamansari Hasil Analisis uji homogenitas Data Awal

\begin{tabular}{lcrrrrr}
\hline Kelas & \multicolumn{7}{c}{$\mathrm{Dk}$} & \multicolumn{2}{c}{$\frac{1}{d k}$} & $S_{i}^{2}$ & $\log S_{i}^{2}$ & $(\mathrm{dk}) \log S_{i}^{2}$ & $(\mathrm{dk}) S_{i}^{2}$ \\
\hline EK(2) & 26 & 0,038 & 51,601 & 1,712 & 44,529 & 1341,630 \\
EK(3) & 16 & 0,062 & 174,235 & 2,241 & 35,858 & 2787,765 \\
KK(1) & 11 & 0,091 & 125,091 & 2,097 & 23,069 & 1376 \\
Jumlah & 53 & 0,192 & 350,927 & 6,051 & 103,457 & 5505,394 \\
$S^{2}$ & 103,875 & B & 106,875 & $\chi_{\text {hitung }}^{2}$ & 7,871 & \\
Log $S^{2}$ & 2,016 & Ln 10 & 2,302 & $\chi_{\text {tabel }}^{2}$ & 34,8 & \\
\hline
\end{tabular}

Berdasarkan Tabel 3 hasil analisis uji homogenitas data awal diperoleh $\chi^{2}$ hitung $=7,871 \mathrm{dk}=53$ dan taraf nyata $\alpha=0,05, \chi^{2}$ tabel $=34,8$ karena (homogen).

$\chi_{\text {hitung }}^{2}<\chi_{\text {tabel }}^{2}$ maka $\mathrm{H}_{0}$ diterima. Sehingga ketiga sampel kelas memiliki varians populasi yang sama

Tabel 5. Siswa Kelas V SD N Tamansari Hasil Analisis Uji Homogenitas Data Akhir

\begin{tabular}{|c|c|c|c|c|c|c|}
\hline Kelas & Dk & $\frac{1}{d k}$ & $S_{i}^{2}$ & $\log S_{i}^{2}$ & $(\mathrm{dk}) \log S_{i}^{2}$ & $(\mathrm{dk}) S_{i}^{2}$ \\
\hline $\mathrm{EK}(2$ & 26 & 0,038 & 44,717 & 1,650 & 42,912 & 1162,666 \\
\hline $\mathrm{EK}(3)$ & 16 & 0,062 & 160,000 & 2,204 & 35,265 & 2560,000 \\
\hline $\mathrm{KK}(1)$ & 11 & 0,091 & 510,060 & 2,707 & 29,783 & 5610,666 \\
\hline Jumlah & 53 & 0,192 & 714,778 & 6,562 & 107,962 & 9333,333 \\
\hline$s^{2}$ & 176,100 & B & 119,025 & $\chi_{\text {hitung }}^{2}$ & 25,474 & \\
\hline $\log S^{2}$ & 2,245 & Ln 10 & 2,3026 & $\chi_{\text {tabel }}^{2}$ & 34,8 & \\
\hline
\end{tabular}

Berdasarkan tabel 4 hasil analisis uji homogenitas data Akhir diperoleh $\chi^{2}{ }_{\text {hitung }}=25,474$ dan hasil tersebut akan dibandingakan dengan $\chi^{2}$ tabel.

Untuk $\alpha=5 \%$ dengan $\mathrm{dk}=53$, diperoleh $\chi_{(0,05)(53)}^{2}=34,8$

karena $\chi^{2}$ hitung $<\chi^{2}$ tabel maka $\mathrm{H}_{0}$ diterima. Sehingga ketiga sampel kelas memiliki varians populasi yang sama (homogen).

Tabel 6. Siswa Kelas V SD N Tamansari Hasil Analisis Varians Data Awal

\begin{tabular}{llccc}
\hline \multicolumn{1}{c}{ Sumber Variasi } & \multicolumn{1}{c}{ Dk } & JK & KT & F \\
\hline Rata-rata & 1 & 105966,000 & 105966,000 & \\
Antar Kelompok & 2 & 1184,606 & 592,303 & \\
Dalam Kelompok & 53 & 8641,394 & 163,045 & 3,633 \\
Total & 56 & 115792,000 & - & \\
\hline
\end{tabular}

Hasil perhitungan menunjukan bahwa $\mathrm{F}_{\text {hitung }}=3,633$ dari Daftar distribusi $\mathrm{F}$ dengan dk pembilang $=2$, $\mathrm{dk}$ penyebut $=56$ dan peluang $(\alpha=0,05)$ didapat

$\mathrm{F}_{\text {tabel }}=3,18$ Ternyata $\mathrm{F}_{\text {hitung }}>\mathrm{F}_{\text {tabel }}$ sehingga hipotesis $\mathrm{H}_{0}$ ditolak. Jadi, terdapat perbedaan antara rata-rata kemampuan awal siswa antar ketiga kelas tersebut. 
Tabel 7. (Hipotesis 1) Siswa Kelas V SD N Tamansari. Hasil Analisis Akhir Uji Anava Satu Arah

\begin{tabular}{cccrc}
\hline Sumber Variasi & Dk & JK & KT & F \\
\hline Rata-rata & 1 & 312007,143 & 312007,143 & \\
Antar Kelompok & 2 & 2291,524 & 1145,762 & 4,183 \\
Dalam Kelompok & 53 & 14517,333 & 273,912 & \\
Total & 56 & 328816,000 & & \\
\hline
\end{tabular}

Dari hasil perhitungan anava diatas dapat disimpulkan bahwa Ho ditolak, maka artinya adalah terdapat perbedaan hasil belajar siswa antar kelas eksperimen 1, kelas eksperimen 2, dan kelas kontrol.

dengan taraf signifikan $(\alpha)=5 \%$, dk pembilang $=2$, dan dk penyebut $=56$, Maka diperoleh harga $\mathrm{F}_{\text {hitung }}=$ 4,183 , dan $\mathrm{F}_{\text {tabel }}=3,18$, karena $\mathrm{F}_{\text {hitung }}>\mathrm{F}_{\text {tabel }}$ yaitu $4,183>3.180$, maka Ho ditolak.

Tabel 8. (Hipotesis 2) Siswa Kelas V SD N Tamansari Hasil Analisis Uji t Kelas Eksperimen 1 dan Kelas kontrol

\begin{tabular}{lccccc}
\hline \multicolumn{1}{c}{ Subjek } & Kelas & $\mathrm{t}_{\text {hitung }}$ & $\mathrm{t}_{\text {tabel }}$ & Kriteria & Keterangan \\
\hline Kelas V & E1 & & & & \\
SDN & & 2,718 & 2,201 & $\mathrm{t}_{\text {hitung }}>\mathrm{t}_{\text {tabel }}$ & $\mathrm{H}_{0}$ ditolak \\
Tamansari & KK & & & & \\
\hline
\end{tabular}

Uji t satu pihak (Hipotesis 2) digunakan untuk mengetahui apakah hasil belajar siswa yang mendapat Model Pembelajaran RME lebih baik dari pada model pembelajaran konvensional. Dari perhitungan secara manual didapat taraf signifikan $(\alpha)=5 \%, \mathrm{dk}=37$, maka diperoleh harga $\mathrm{t}_{\text {hitung }}=2,718$, dan $\mathrm{t}_{\text {tabel }}=2,021$, karena $t_{\text {hitung }}>t_{\text {tabel }}$ yaitu $2,718,>2,021$, maka Ho ditolak dan Ha diterima.

Dari hasil perhitungan diatas dapat dapat disimpulkan bahwa hasil belajar siswa yang mendapatkan Model RME lebih baik dari pada hasil belajar siswa yang mendapatkan model pembelajaran Konvensional.

Tabel 9 (Hipotesis 3) Siswa Kelas V SD N Tamansari Hasil Analisis Uji t Kelas Eksperimen 2 dan Kelas kontrol

\begin{tabular}{lrrrrl}
\hline \multicolumn{1}{c}{ Subjek } & Kelas & $\mathrm{t}_{\text {hitung }}$ & $\mathrm{t}_{\text {tabel }}$ & kriteria & Keterangan \\
\hline Kelas V & E2 & & & & \\
SDN & & 2,257 & 2,021 & $\mathrm{t}_{\text {hitung }}>\mathrm{t}_{\text {tabel }}$ & $\mathrm{H}_{0}$ ditolak \\
Tamansari & KK & & & & \\
\hline
\end{tabular}

Uji t satu pihak (Hipotesis 3) digunakan untuk mengetahui apakah hasil belajar siswa yang mendapat Model Pembelajaran Snowball Throwing lebih baik dari pada model pembelajaran konvensional. Dari perhitungan secara manual didapat taraf signifikan $(\alpha)=5 \% \mathrm{dk}=27$, maka diperoleh harga $\mathrm{t}_{\text {hitung }}=2,257$, dan $t_{\text {tabel }}=2,021$, karena $t_{\text {hitung }}>t_{\text {tabel }}$ yaitu 2,257, $>2,021$, maka Ho ditolak dan Ha diterima.

Dari hasil perhitungan di atas dapat disimpulkan bahwa hasil belajar siswa yang mendapatkan Model Pembelajaran Snowball Throwing lebih baik dari pada hasil belajar siswa yang mendapatkan model pembelajaran konvensional.

Uji ketuntasan belajar (Hipotesis 4)

Rumus Uji Ketuntasan

Ketentuan Belajar Klasikal

Tuntas belajar $=\frac{\text { banyak siswa yang twntas }}{\text { banyak siswa seluruhnya }} \times 100 \%$

Suatu kelas dikatakan tuntas belajar secara klasikal jika presentase yang dicapai sekurang-kurangnya $65 \%$

Kriteria pengujian

Jika KBK $<65 \%$ maka Ho diterima, Jika KBK $\geq 65 \%$ maka Ho ditolak.

Perhitungan dengan rumus Ketuntasan Belajar Klasikal $R M E$

Tuntas belajar $=\frac{\text { banyak siswa yang tuntas }}{\text { banyak siswa seluruhnya }} \times 100 \%$

Tuntas belajar $=\frac{22}{27} \times 100 \%$

$=81,4 \%$

Perhitungan dengan rumus Ketuntasan Belajar Klasikal Snowball Throwing

Tuntas belajar $=\frac{\text { banyaknya siswa yang tuntas }}{\text { banyak siswa selurwhnya }} \times 100 \%$ 
Tuntas belajar $=\frac{13}{17} \times 100 \%$

$$
=76,5 \%
$$

Uji ketuntasan Belajar Klasikal (Hipotesis 4) digunakan untuk mengetahui apakah kelas yang mendapat model Pembelajaran RME dan Snowball Throwing mencapai ketuntasan belajar. Dari perhitungan secara manual didapat 22 siswa kelas $R M E$ dinyatakan tuntas dan 13 siswa kelas Snowball dinyatakan tuntas, maka diperoleh harga KBK kelas $R M E=81,4 \%$ dan KBK kelas Snowball Throwing $=76,5 \%$. karena KBK $>65 \%$ yaitu 70,4\% $>65 \%$ dan76,5.\% $>65 \%$ maka Ho ditolak dan Ha diterima.

Dari hasil perhitungan diatas dapat disimpulkan bahwa hasil belajar siswa pada pembelajaran model Realistic Mathematic Education dan model pembelajaran Snowball Throwing mencapai ketuntasan.

Pembahasan dari analisis data awal diperoleh data yang berdistribusi normal dan homogen serta hasil uji kesamaaan rata-rata atau anava menunjukan bahwa $F_{\text {hitung }}<F_{\text {tabel }}$ sehingga dapat disimpulkan bahwa sampel berasal dari keadaan awal yang sama. Kemudian ketiga sampel diberikan perlakuan yang berbeda. Pada kelompok eksperimen I RME, pada kelompok II diberikan perlakuan menggunakan model Snowball Throwing, sedangkan kelas kontrol menggunakan model pembelajaran konvensional. Sehingga diperoleh beberapa kesimpulan.

Untuk Hipotesis I menunjukan bahwa Ho ditolak. Dengan menggunakan uji Analisis akhir Anava satu arah, dengan taraf signifikan $(\alpha)=5 \%$, dk pembilang $=2$, dan dk penyebut $=56$, Maka diperoleh harga $F_{\text {hitung }}=$ 4,183 , dan $F_{\text {tabel }}=3,18$, karena $F_{\text {hitung }}>F_{\text {tabel }}$ yaitu 4,183 $>3.180$, maka Ho ditolak Sehingga ada perbedaan efektifitas siswa yang mendapatkan model pembelajaran RME, model pembelajaran Snowball Throwing, dengan siswa yang mendapatkan pembelajaran dengan model konvensional. Perbedaan tersebut terjadi karena keunggulan yang terdapat pada setiap metode pembelajaran.

Model pembelajaran $R M E$ mempunyai keunggulan dimana siswa akan menjadi lebih aktif dan terlatih untuk menentukan jawaban-jawaban dari pertanyaan yang mendalamai isi bacaan atau teks tersebut. Selain itu, siswa juga dapat lebih terlatih dalam bekerjasama di dalam sebuah kelompok untuk saling bertukar pendapat dalam memahami konsep materi yang disajikan dalam uraian teks. Sehingga metode ini akan meningkatkan daya ingat siswa dari pemahaman suatu bacaan .

Sedangakan model pembelajaran Snowball Throwing mempunyai keunggulan seperti dengan menggunakan pembelajaran dengan permainan menyenangkan akan membuat siswa antusias dan senang mengikuti pembelajaran yang di lakukan.

Berdasarkan Hipotesis 2 menunjukan bahwa Ho ditolak. Dengan menggunakan Analisis Uji t satu pihak. taraf signifikan $(\alpha)=5 \%, \mathrm{dk}=37$, maka diperoleh harga $\mathrm{t}_{\text {hitung }}=2,718$, dan $\mathrm{t}_{\text {tabel }}=2,021$, karena $\mathrm{t}_{\text {hitung }}>\mathrm{t}_{\text {tabel }}$

yaitu 2,718, $>2,021$, maka Ho ditolak dan Ha diterima. Sehingga dapat disimpulkan bahwa keefektifan model pembelajaran $R M E$ terdapat perbedaan dengan siswa yang diberi pembelajaran model konvensional.

Hal ini disebabkan model pembelajaran $R M E$ lebih baik dibandingkan dengan model pembelajaran konvensioanal. Karena model pembelajaran RME dimana siswa akan menjadi lebih aktif dan terlatih untuk memikirkan jawaban-jawaban dari pertanyaan yang ada dalam materi. Sehingga metode ini akan meningkatkan daya ingat siswa dari pemehaman materi.

Berdasarkan Hipotesis 3 menunjukan bahwa Ho ditolak. Dengan menggunakan Analisis Uji t satu pihak didapat taraf signifikan $(\alpha)=5 \% \mathrm{dk}=27$, maka diperoleh harga $\mathrm{t}_{\text {hitung }}=2,257$, dan $\mathrm{t}_{\text {tabel }}=2,021$, karena $\mathrm{t}_{\text {hitung }}>$ $\mathrm{t}_{\text {tabel }}$ yaitu 2,257, $>2,021$, maka Ho ditolak dan Ha diterima. Sehinga dapat disimpulkan bahwa keefektifan model pembelajaran Snowball Throwing terdapat perbedaan dengan siswa yang diberi model pembelajaran konvensional.

Berdasarkan Hipotesis 4 menunjukan bahwa Ho di tolak. Dengan menggunakan Uji Ketuntasan Belajar Klasikal. dari perhitungan secara manual didapat 22 siswa kelas $R M E$ dinyatakan tuntas dan 13 siswa kelas Snowball dinyatakan tuntas, maka diperoleh harga KBK kelas $R M E=81,4 \%$ dan KBK kelas Snowball Throwing $=76,5 \%$. karena KBK $>65 \%$ yaitu $70,4 \%>65 \%$ dan76,5.\% $>65 \%$ maka Ho ditolak dan Ha diterima. Sehingga dapat simpulkan hasil belajar siswa pada pembelajaran model Realistic Mathematic Education dan model pembelajaran Snowball Throwing mencapai ketuntasan.

Hal ini sependapat dengan Bruner dalam Siregar (2010: 33), teori ini menjelaskan bahwa proses belajar akan berjalan dengan baik dan kreatif jika guru memberi kesempatan kepada siswa untuk menemukan suatu aturan melalui contoh-contoh yang menggambarkan aturan yang menjadi sumbernya. Dengan menggunakan model pembelajaran snowball throwing memiliki beberapa keunggulan,yang salah satunya yaitu siswa mendapat kesempatan untuk mengembangkan kemampuan berpikir karena diberi kesempatan untuk membuat soal dan diberikan pada siswa lain. Sehingga hasilnya akan tercapai dalam pembelajaran dalam hal ini siswa dilatih untuk berani untuk membuat pertanyaan untuk temannya dan sekaligus menjawabnya. Guru disini hanyalah sebagai fasilitator dan juga pembimbing, pembelajaran yang berpusat kepada siswa. 
Hal sependapat dengan Jarmita dan Hazami (2013) dalam $R M E$, pembelajaran tidak dimulai dari rumus, pengertian atau sifat-sifat, kemudian dilanjutkan dengan pembahasan contoh-contoh, seperti yang selama ini di sekolah-sekolah. Namun rumus, pengertian dan sifat-sifat tersebut diharapkan ditemukan sendiri oleh siswa melalui bimbingan kontekstual yang diberikan awal pembelajaran oleh guru.karena aktivitas siswa baik secara fisik maupun mental merupakan syarat mutlak bagi berlangsungnya interaksi belajar mengajar.

\section{Simpulan}

Berdasarkan pembahasan hasil penelitian yang didasarkan pada analisis dan statistik dan kenyataan di lapangan sehingga peneliti dapat menyimpulkan bahwa:

1. Terdapat perbedaan hasil belajar siswa antara kelas yang menggunakan model pembelajaran $R M E$, model pembelajaran Snowball Throwing, model pembelajaran konvensional.

2. Hasil belajar antara siswa kelas yang diberikan perlakuan menggunakan model pembelajaran $R M E$, lebih baik dari pada hasil belajar kelas yang diberikan perlakuan model pembelajaran konvensional.

3. Hasil belajar siswa antara kelas yang diberikan perlakuan menggunakan model pembelajaran Snowball Throwing lebih baik dari pada kelas yang di berikan perlakuan model pembelajaran konvensional.

4. Hasil belajar siswa dengan menggunakan model pembelajaran Realistic Mathematic Education dan model pembelajaran Snowball Throwing telah mencapai ketuntasan belajar.

\section{Daftar Pustaka}

Abdurrahman, Mulyono. 2012. Anak Berkesulitan Belajar: Teori, Diagnosis, dan Remediasinya. Jakarta: Rineka Cipta.

Aunurrohman. 2013. Belajar dan Pembelajaran. Bandung: Alfabeta.

Arifin, Zaenal. 2014. Evaluasi Pembelajaran. Jakarta: Direktorat Jenderal Pendidikan Islam, Kementrian Agama RI.

Arikunto, Suharsimi, Cepi Safrudin A. 2009. Evaluasi Program Pendidikan: Pedoman Teoritis Praktis Bagi Mahasiswa dan Praktisi Pendidikan.

Arsyad, Azhar. 2011. Media Pembelajaran. Jakarta: Raja Grafindo Persada.

Dimyati.Mudjiono. 2009. Belajar dan Pembelajaran. Jakarta: PT.

Rineka Cipta

Jarmita, Hazami.2013. Ketuntasan Hasil Belajar Siswa Melalui Pendekatan Realistic Mathematic Education (RME) Pada Materi Perkalian. Vol.XIII,No.2, Februari 2013.

https://scholar.google.co.id/scholar?start=10\&q=rme+matematika+hasil+belajar\&hl=id\&as_sdt=0,5\#d=g s_qabs\&u=\%23p\%3Dfwq48921oMJ

Kusumawati, Noviana. 2013. Pengaruh Kemampuan Komunikasi dan Pemecahan masalah terhadap Hasil Belajar Siswa dengan Pembelajaran Realistic Mathematic Education (RME).

Vol.1,No.1, Januari 2013, ISSN 2303-3983.

https://scholar.google.co.id/scholar?hl=id\&as_sdt=0\%2C5\&q=pengaruh+kemampuan+komunikasi+dan+ pemecahan+masalah+matematika+terhadap+hasi+belajar+siswa+dengan+pembelajaran+rme \&btnG=\#d= gs_qabs\&u=\%23p\%3DiepjGKDHgf4J

Margono, S. 2010. Metodologi Penelitian Pendidikan. Jakarta: Asdi Mahastya.

Shohimin, Aris. 2017. 68 Model Pembelajaran Inovatif dalam Kurikulum 2013. Yogjakarta: Ar-ruzz Media.

Siregar, Eveline dan Nara, Harini. 2011. Teori Belajar dan Pembelajaran. Bogor : Ghalia Indonesia.

Slameto. 2010. Belajar dan Faktor-Faktor Yang Mempengaruhi. Jakarta: PT. Rineka Cipta

Sudjana. 2005. Metode Statistika. Bandung: Tarsito.

Sudjana, Nana. 2014. Dasar-Dasar Proses Belajar Mengajar. Bandungan: Sinar Baru Algensindo

Sugiyono. 2017. Metode Penelitian Kuantitatif Kualitatif dan R \& D. Bandung: Alfabeta.

Trianto. 2011. Pengantar Penelitian Pendidikan Bagi Pengembangan Profesi Pendidikan dan Tenaga Kependidikan. Ed. Titik Triwulan Tutik. Jakarta: Kencana Prenada Media Group. 